\title{
Patent Ductus Arteriosus of the Preterm Infant
}

\author{
Shannon E.G. Hamrick, MD, ${ }^{a, b}$ Hannes Sallmon, MD, ${ }^{c}$ Allison T. Rose, MD, ${ }^{a}$ Diego Porras, MD, ${ }^{d}$ Elaine L. Shelton, PhD, \\ Jeff Reese, MD, ${ }^{\text {e Georg Hansmann, MD, PhD }}{ }^{f}$
}

Postnatal ductal closure is stimulated by rising oxygen tension and withdrawal of vasodilatory mediators (prostaglandins, nitric oxide, adenosine) and by vasoconstrictors (endothelin-1, catecholamines, contractile prostanoids), ion channels, calcium flux, platelets, morphologic maturity, and a favorable genetic predisposition. A persistently patent ductus arteriosus (PDA) in preterm infants can have clinical consequences. Decreasing pulmonary vascular resistance, especially in extremely low gestational age newborns, increases left-to-right shunting through the ductus and increases pulmonary blood flow further, leading to interstitial pulmonary edema and volume load to the left heart. Potential consequences of left-to-right shunting via a hemodynamically significant patent ductus arteriosus (hsPDA) include increased risk for prolonged ventilation, bronchopulmonary dysplasia, necrotizing enterocolitis or focal intestinal perforation, intraventricular hemorrhage, and death. In the last decade, there has been a trend toward less aggressive treatment of PDA in preterm infants. However, there is a subgroup of infants who will likely benefit from intervention, be it pharmacologic, interventional, or surgical: (1) prophylactic intravenous indomethacin in highly selected extremely low gestational age newborns with PDA $(<26+0)$ 7 weeks' gestation, $<750 \mathrm{~g}$ birth weight), (2) early targeted therapy of PDA in selected preterm infants at particular high risk for PDA-associated complications, and (3) PDA ligation, catheter intervention, or oral paracetamol may be considered as rescue options for hsPDA closure. The impact of catheter-based closure of hsPDA on clinical outcomes should be determined in future prospective studies. Finally, we provide a novel treatment algorithm for PDA in preterm infants that integrates the several treatment modalities in a staged approach.

The fetal ductus arteriosus (DA) diverts cardiac output away from the lungs toward the placenta to support systemic oxygenation. After delivery, circulatory adaptation depends on DA closure within the first days of life. In preterm infants, DA closure frequently fails to occur because of immature structures and responses to constrictive mechanisms. A persistently patent ductus arteriosus (PDA) can have clinical consequences depending on the degree of left-to-right shunting and ductal steal. The increase in pulmonary blood flow in the setting of prematurity can lead to pulmonary edema, respiratory deterioration, and diminished gastrointestinal, renal, and cerebral blood flow. ${ }^{1}$ The incidence of PDA (ie, an open DA beyond the first 3 postnatal days) exceeds $50 \%$ in preterm infants $\leq 28$ weeks' gestational age. $^{2}$ Although spontaneous closure rates in these infants are high, historical practice has led to medical or surgical therapy in $60 \%$ to $70 \%$ of preterm abstract

Divisions of ${ }^{a}$ Neonatology and ${ }^{b}$ Cardiology, Department of Pediatrics, Emory University and Children's Healthcare of Atlanta, Atlanta, Georgia; ${ }^{C}$ Department of Pediatric Cardiology, Charité University Medical Center, Berlin, Germany; ${ }^{d}$ Department of Cardiology, Boston Children's Hospital and Harvard Medical School, Harvard University, Boston, Massachusetts; ${ }^{e}$ Division of Neonatology, Vanderbilt University Medical Center, Nashville, Tennessee; and ${ }^{f}$ Department of Pediatric Cardiology and Critical Care, Hannover Medical School, Hannover, Germany

Drs Hamrick and Hansmann conceptualized and designed this review article, drafted the initial manuscript with input from all authors, and edited and revised the manuscript; Drs Sallmon, Rose, Porras, Shelton, and Reese contributed text and/or display items and revised the manuscript for important intellectual content; and all authors approved the final manuscript as submitted.

DOI: https://doi.org/10.1542/peds.2020-1209

Accepted for publication Jun 30, 2020

Address correspondence to Georg Hansmann, MD, PhD, Department of Pediatric Cardiology and Critical Care, Hannover Medical School, Carl-Neuberg-

Strasse. 1, 30625 Hannover, Germany.

E-mail: georg.hansmann@gmail.com

PEDIATRICS (ISSN Numbers: Print, 0031-4005; Online, 1098-4275).

Copyright (C) 2020 by the American Academy of Pediatrics

FINANCIAL DISCLOSURE: The authors have indicated they have no financial relationships relevant to this article to disclose.

FUNDING: Dr Hansmann receives funding from the German Research Foundation (HA4348/6-2 KF0311, HA4348/2-2), the Federal Ministry of Education and Research (BMBF ViP + program 03VP08053; BMBF 01KC2001B), and the European Pediatric Pulmonary Vascular Disease Network (www.pvdnetwork.org). Dr Shelton is funded by the National Institutes of Health (HL132805) and the American Heart Association (15SDG25280015). Dr Reese is funded by the National Institutes of Health (HL128386). Funded by the National Institutes of Health (NIH)

To cite: Hamrick SEG, Sallmon H, Rose AT, et al. Patent Ductus Arteriosus of the Preterm Infant. Pediatrics. 2020;146(5):e20201209 
infants $<28$ weeks' gestational age. ${ }^{3}$ However, because of high spontaneous DA closure rates in these infants, there has been a shift toward less frequent and invasive treatment in the last decade (watchful waiting without intervention). ${ }^{4}$ Nevertheless, the mid- and long-term consequences of prolonged ductal patency are still unclear. ${ }^{5-10}$

\section{BIOLOGICAL BASIS OF PDA}

\section{Embryology of DA and Genetic} Syndromes Associated With PDA

During embryogenesis, paired pharyngeal arch arteries (PAAs) form and connect the heart and dorsal aorta. The DA develops from the distal portion of the left sixth PAA, which is ultimately composed of endothelium derived from the second heart field and smooth muscle derived from neural crest progenitor cells. ${ }^{11}$ Abnormal PAA development can cause a variety of congenital heart defects, including PDA.

Although PDA is generally considered a sporadic defect impacted by extrinsic factors, genetic studies have identified syndromes that frequently manifest PDA (Table 1). ${ }^{12}$ Still, only $10 \%$ of PDA cases are associated with chromosomal abnormalities. ${ }^{13}$

Therefore, single-nucleotide polymorphisms associated with nonsyndromic PDA may be more informative regarding genetic regulation of the more common sporadic cases of $\mathrm{PDA}^{14,15}$ (Table 1 ).

\section{Mechanisms Underlying Postnatal Closure of the DA}

The fetal DA has intrinsic tone and requires dilating factors (nitric oxide, prostaglandin $\mathrm{E}_{2}$, adenosine, atrial natriuretic peptide, carbon monoxide, and potassium channels) to maintain its patency ${ }^{16}$ At birth, DA closure occurs by (1) functional constriction and (2) anatomic remodeling resulting in formation of the ligamentum arteriosum. Initial DA constriction occurs as pulmonary vascular resistance (PVR) falls, systemic vascular resistance increases, circulating prostaglandin $\mathrm{E}$ (PGE) levels decline, and respiration is initiated, triggering a sharp increase in arterial oxygen tension. Complete closure is achieved by a combination of physiologic, molecular, and structural factors (Fig 1A). ${ }^{1,17-21}$

\section{Mechanisms Underlying Persistent Patency of the DA in Preterm Infants}

Spontaneous PDA closure occurs less frequently in preterm infants at $<28$ weeks' gestation. The time it takes to achieve closure is inversely proportional to gestational age at birth, with some vessels requiring months to years to close. ${ }^{22}$ PDA in preterm infants is considered the result of generalized immaturity of the smooth muscle and biochemical oxygen sensing mechanisms (Fig 1B). Indeed, the preterm ductus is transcriptionally distinct from term vessels. ${ }^{23-25}$

The preterm DA is also structurally different from mature vessels. The absence or rudimentary formation of intimal cushions in the preterm DA is associated with failure to close. ${ }^{13}$

Similarly, preterm vessels have fewer layers of contractile smooth muscle cells and lack vasa vasorum. ${ }^{26}$ This can result in partial postnatal constriction without the ischemiadriven remodeling critical for permanent closure.

Preterm DAs are also subjected to extrinsic factors that make vessel closure more difficult (Fig 1B). Echocardiographic studies reveal that preterm DAs exposed to sustained bidirectional, right-to-left, or lowvelocity blood flow were more likely to remain patent and were resistant to pharmacologic therapy, ${ }^{27,28}$ thus highlighting the role of hemodynamic forces and PVR in modulating DA tone. In addition, studies on the role of platelets have yielded conflicting results. In some, an association between low platelet number and delayed spontaneous or pharmacologic PDA closure was identified in very preterm infants $^{29-32}$; however, platelet transfusions failed to accelerate PDA closure in thrombocytopenic premature infants. ${ }^{33}$ In other studies, it was argued that platelet function, not number, was the key regulator of preterm PDA status. ${ }^{34,35}$

\section{CLINICAL CONSEQUENCES OF HEMODYNAMICALLY SIGNIFICANT PATENT DUCTUS ARTERIOSUS}

\section{Multiorgan Comorbidities Associated With Patency of the DA}

A left-to-right ductal shunt causes increased pulmonary blood flow and ductal steal from the systemic circulation and thus can have adverse effects on premature infants, ${ }^{1}$ although a causal relationship is not well defined. ${ }^{36}$

\section{Pulmonary Sequelae and Chronic Lung Disease}

The pathologic effects of excess leftto-right ductal shunting, namely increased lung fluid, decreased pulmonary compliance, and impaired oxygenation, is associated with increased need for respiratory support and mechanical ventilation, contributing to lung injury. ${ }^{37}$

PDA poses the risk for hemorrhagic pulmonary edema due to pulmonary overcirculation, redistribution of hydraulic pressures to downstream capillary filtration sites, left-sided cardiac dysfunction, and consecutive postcapillary (venous) pulmonary hypertension. ${ }^{37}$ The downstream cardiopulmonary effects of a large PDA include left atrium (LA) and left ventricle (LV) overload leading to LA and LV dilation. Initial hyperdynamic systolic function later develops into decreased LV systolic function. In a large hemodynamically significant patent ductus arteriosus (hsPDA) with unrestrictive pulmonary artery (PA) flow, PA pressure is elevated to at least a systemic level, increasing 
TABLE 1 Genetic Factors Associated With PDA

\begin{tabular}{lc}
\hline Human Syndromes (Gene) & Nonsyndromic SNPs (Accession Number) \\
\hline 22 111.2 deletion & Increased Risk of PDA \\
Char (TFAP2B) & TFAP2B (rs987237) \\
Cantu (ABCC9, KCNJ8) & TRAF1 (rs1056567) \\
Noonan (PTPN1) & AGTR1 (rs5186) \\
Mowat-Wilson (SMADIP1) & Decreased Risk of PDA \\
DiGeorge (TBX1) & PTGIS (rs493694, rs693649) \\
Holt-Oram (TBX5) & ESR1 (rs2234693) \\
Loeys-Dietz (TGFBR1 and TGFBR2) & IFN- $\gamma$ (rs2430561) \\
Rubinstein-Taybi (CREBP) & \\
Periventricular heterotopia (FLNA) &
\end{tabular}

PDA is associated with several genetic syndromes. Several SNPs have also been associated with cases of nonsyndromic PDA. ABCC9, ATP binding cassette subfamily $C$ member 9; AGTR1 angiotensin II receptor type 1; CREBP, cyclic adenosine monophosphate-response element binding protein; ESR1, estrogen receptor 1; FLNA, filamin A; IFN- $\gamma$, interferon- $\gamma$ KCNJ8, potassium inwardly rectifying channel subfamily J member 8; PTGIS, prostaglandin I2 synthase; PTPN11, protein tyrosine phosphatase nonreceptor type 11; SMADIP1, SMAD-interacting protein 1; SNP, single-nucleotide polymorphism; TBX1, T-box transcription factor 1; TBX5, T-box transcription factor 5; TFAP2B, transcription factor AP-2- $\beta$; TGFBR1, transforming growth factor- $\beta$ receptor type 1; TGFBR2, transforming growth factor- $\beta$ receptor type 1; TRAF1, tumor necrosis factor receptor associated factor 1

flow and/or shear stress injury, endothelial cell dysfunction, and eventual pulmonary hypertension $^{38,39}$ with increased PVR. In the acute phase of PDA exposure, the incidence of serious pulmonary hemorrhage in infants weighing $<1000 \mathrm{~g}$ is $10 \%$. $^{40}$ Prophylaxis with indomethacin reduced the risk for serious pulmonary hemorrhage by $35 \%$ over the first week of life; $80 \%$ of this beneficial effect was explained by reduced risk for PDA. ${ }^{41}$ Similarly, infants at $<29$ weeks' gestation who were selectively treated prophylactically by 6 hours of age had less pulmonary hemorrhage than controls ( $2 \%$ vs $21 \%$ ). ${ }^{42}$

Sustained PDA exposure may contribute to bronchopulmonary dysplasia (BPD). ${ }^{43-45}$ However, an association between PDA and BPD has not been found in other studies, $8,22,46$ suggesting the need for controlled studies. In the Patent Ductus Arteriosus: To Leave It Alone or Respond and Treat Early (PDATOLERATE) trial, early versus late PDA treatment was compared in a prospective multicenter randomized controlled trial (RCT). By prespecified secondary analysis, there was no difference in the development of BPD (relative risk [RR] 0.94; 95\% confidence interval [CI] 0.70-1.3) or BPD or death before 36 weeks (RR 1.00; $95 \%$ CI $0.80-1.3$ ) between the early treatment arm and the conservative treatment arm. ${ }^{47}$ However, among 137 infants screened for the trial, but not enrolled because of lack of physician equipoise, the combined outcome of home oxygen or death for treated infants was lower than that in the enrolled cohort. ${ }^{48}$

The binary variable of PDA versus no PDA may not be as important as the duration of exposure. In infants at $<28$ weeks' gestation surviving for at least 7 days, the risk of BPD or death increased in infants after 7 days of exposure to a moderate-to-large PDA shunt (odds ratio 2.12; 95\% CI 1.04-4.32). ${ }^{49}$ For the singular outcome of BPD, exposure to a PDA was required for at least 14 days (odds ratio 4.09; 95\% CI $2.22-7.22){ }^{49}$

\section{Neurologic Morbidities}

Intraventricular hemorrhage (IVH), periventricular leukomalacia, and school-aged performance are important outcomes associated with prematurity. The role of PDA in these outcomes versus the effect of PDA treatments is hard to tease apart. The Trial of Indomethacin Prophylaxis in Preterms (TIPP) revealed decreased IVH rates after prophylactic indomethacin but without long-term benefit. $^{40}$ The data for prophylactic ibuprofen or paracetamol are less compelling. ${ }^{50,51}$ Prophylactic surgical ligation provides no benefit in terms of $\mathrm{IVH}^{52}$ and surgical ligation itself may be an independent risk factor for poor neurodevelopmental outcome. ${ }^{53,54}$

PDA decreases regional cerebral oxygenation saturation and increases fractional tissue oxygen extraction in preterm infants. ${ }^{55}$ Follow-up termequivalent MRIs reveal decreased cerebellar volumes in infants requiring surgical ligation. ${ }^{56}$

Infants treated with pharmacotherapy or ligation had worse neurodevelopmental outcomes at 2 to 3 years of age than infants without PDA or without treatment of PDA; however, no adjustments were made for postnatal confounders, such as necrotizing enterocolitis (NEC). ${ }^{57}$ In one long-term study of preterm infants born in the 1980s, no difference in cognitive development or behavior was found between infants with and without a PDA at ages 3,8 , and 18 years. $^{58}$ This cohort was likely healthier and more mature than the infants at 22 to 26 weeks' gestation of today's NICUs; however, 18-year follow-up is unusual, and these findings should be considered in context.

\section{NEC or Focal Intestinal Perforation}

Diminished intestinal blood flow in the setting of a ductal shunt may predispose preterm infants to NEC or 
A

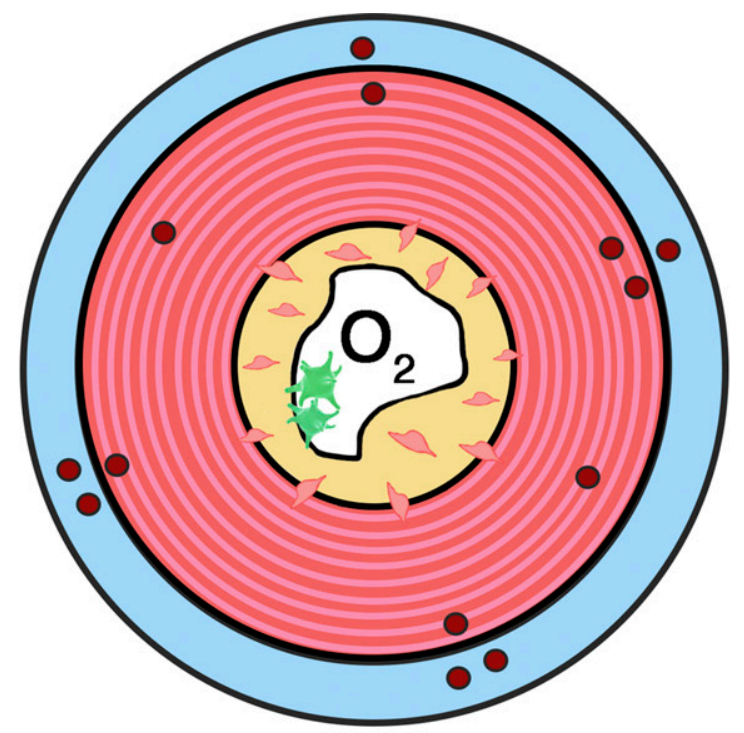

B

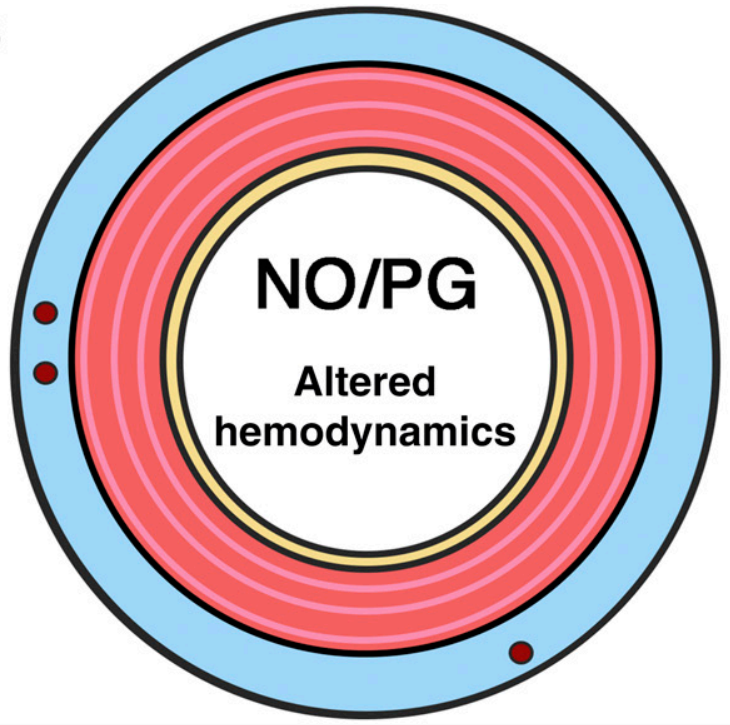

Factors Promoting Preterm DA Patency

\begin{tabular}{|c|c|}
\hline Factors Promoting Postnatal DA Closure & Factors Promoting Preterm DA Patency \\
\hline \multicolumn{2}{|c|}{ Molecular Factors } \\
\hline $\begin{array}{l}\text { Increased } \mathrm{O}_{2} \text { tension } \\
\text { Decreased vasodilating prostaglandins } \\
\text { Activation of cytochrome P450 } \\
\text { Increased endothelin-1 levels } \\
\text { Production of isoprostanes (8-iso-PGF2 } \alpha \text { ) } \\
\left.\text { Inhibition of potassium channels ( } \mathrm{K}_{\mathrm{ATP}}, \mathrm{Kv}, \mathrm{BK}_{\mathrm{Ca}}\right) \\
\text { Activation of transient receptor potential channels } \\
\text { Decrease in intracellular cAMP and/or cGMP levels } \\
\text { Angiotensin II } \\
\text { Bradykinin } \\
\text { Acetylcholine } \\
\text { Norepinephrine } \\
\text { Activation of RhoA, RhoB, Rock1, and Rock2 }\end{array}$ & $\begin{array}{l}\text { Hypoxia } \\
\text { Increased nitric oxide signaling } \\
\text { Increased prostaglandin signaling }\end{array}$ \\
\hline \multicolumn{2}{|c|}{ Physiologic Factors } \\
\hline $\begin{array}{l}\text { Decreased pulmonary vascular resistance } \\
\text { Increased systemic vascular resistance }\end{array}$ & $\begin{array}{l}\text { Prolonged bidirectional or right-to-left blood flow } \\
\text { Low-velocity blood flow }\end{array}$ \\
\hline \multicolumn{2}{|c|}{ Structural Factors } \\
\hline $\begin{array}{l}\text { Mature contractile smooth muscle cells } \\
\text { Prominent intimal cushions } \\
\text { Vasa vasorum } \\
\text { Zone of ischemia and/or necrosis } \\
\text { Platelet adherence to lumen }\end{array}$ & $\begin{array}{l}\text { Thin layer or immature smooth muscle } \\
\text { Insufficient intimal cushion development } \\
\text { Thrombocytopenia or platelet dysfunction }\end{array}$ \\
\hline
\end{tabular}

\section{FIGURE 1}

Factors affecting postnatal DA closure and preterm PDA. A and B, Postnatal DA closure (A) and preterm DA patency (B) are regulated by a combination of molecular, physiologic, and structural factors. Of note, several studies have identified distinct variants in CYP2C9*2 that are associated with failure of PDA closure in response to indomethacin. ${ }^{14,15}$ cAMP, cyclic adenosine monophosphate; cGMP, cyclic guanosine monophosphate; $0_{2}$, oxygen.

focal intestinal perforation (FIP). An RCT from 1989 revealed decreased NEC risk in infants undergoing prophylactic surgical ligation $(8 \% \text { vs } 30 \%)^{52}$; however, most RCTs on prophylactic pharmacotherapy have revealed no difference in NEC rates. ${ }^{50,51}$
Simultaneous exposure to corticosteroids and indomethacin is a known risk for intestinal injury. However, indomethacin for IVH prophylaxis after antenatal steroid exposure was not associated with FIP in extremely low gestational age newborns (ELGANs), although indomethacin for treatment of symptomatic PDA was. ${ }^{59}$ Although there are few data on feeding practices in the presence of PDA, early feeding during indomethacin treatment may improve the time to reach full feedings, ${ }^{60}$ may preserve postprandial mesenteric perfusion, ${ }^{61}$ 
and is not associated with increased risk of NEC or FIP. ${ }^{60-62}$

\section{TREATMENT OF PDA IN THE PRETERM INFANT}

\section{When Is a PDA Hemodynamically Significant?}

There is no consensus on clinical or sonographic criteria that define the need for PDA closure. The determinants of risk for hsPDA we propose are shown in Fig 2. The gold standard for diagnosing a PDA and for assessing its hemodynamic significance is transthoracic echocardiography ${ }^{63,64}$; it not only allows for visualization of the ductus and determination of its size but also identifies shunt direction, systolicdiastolic pattern and velocity, and ventricular and atrial volumes and function. A ductal diameter $\geq 1.5 \mathrm{~mm}$ during the first hours of life is predictive of development of a symptomatic DA in infants $\leq 28$ weeks' gestational age ${ }^{65,66}$; this finding provides a rationale to consider early targeted treatment in selected infants. ${ }^{42,67}$ Several other echocardiographic variables have been used to assess the significance of a PDA: an LA-to-aortic root ratio $\geq 1.4$, LV enlargement, increased mean and diastolic PA flow velocities, and a reversed mitral $\mathrm{E} / \mathrm{A}$ ratio (echocardiographical PW-Doppler variable of early versus late filling as surrogate for diastolic LV function) are reported indicators for pulmonary overcirculation (high Qp/ Qs [ratio of pulmonary/systemic blood flow]) and subsequent increased left heart volume load ${ }^{64}$; however, these measurements depend on preload and have interobserver variability. In addition, retrograde diastolic flow in the descending aorta and low-antegrade or retrograde diastolic flow in systemic arteries (eg, anterior cerebral artery and renal and mesenteric arteries) indicate systemic hypoperfusion and ductal steal
(Fig 2). Additional echocardiographic markers that indicate an hsPDA shunt are reviewed elsewhere. ${ }^{68}$ The diagnosis of hsPDA should be based on a combination of echocardiographic and clinical variables and should incorporate individual risk factors for adverse outcome, such as gestational age, chronological age, and comorbidities. Plasma and urinary biomarkers ${ }^{1}$ and assessments of cerebral and abdominal tissue oxygenation by near-infrared spectroscopy might help identify patients with compromised hemodynamic status ${ }^{69,70}$ because the existing sonographic criteria cannot clearly define the need for PDA closure.

\section{Pharmacologic Ductus Closure by Prostaglandin Inhibition: Cyclooxygenase Inhibitors (Indomethacin and Ibuprofen) and Paracetamol (Acetaminophen)}

Intravenous indomethacin has been the therapeutic mainstay since pharmacotherapy for PDA was introduced to clinical practice. Over the past decade, there has been substantial interest in new regimens and pharmaceutical choices for PDA closure. RCTs from the 1980s were focused on prophylactic, early $(<24$ hours), or symptomatic treatment, typically between 2 and 6 days after birth. ${ }^{1}$ In additional studies, third and fourth treatment categories are now considered: asymptomatic infants $<72$ hours after birth ${ }^{42,64}$ or late symptomatic treatment after watchful waiting. ${ }^{71}$ New formulations, such as oral and intravenous ibuprofen and oral and intravenous paracetamol, broaden but also complicate the landscape once dominated by indomethacin (Table 2). Additionally, use of cyclooxygenase (COX) inhibitors is declining in favor of watchful waiting. 4,72

\section{Indomethacin and Ibuprofen}

Pharmaceutical strategies generally are focused on inhibiting prostaglandin synthesis. COX inhibitors, such as indomethacin or ibuprofen, are the mainstays of treatment. Although paracetamol, which is thought to act at the peroxidation site of COX, has gained attention over the past decade, ${ }^{51}$ it appears less effective than indomethacin or ibuprofen in extreme prematurity. ${ }^{73,74}$ COX inhibitors are less effective in severely preterm infants, likely because of maturational factors in response to prostaglandin inhibition and prevention of intimal cushion formation. ${ }^{1}$

Ibuprofen has less detrimental effects on end-organ perfusion than indomethacin. ${ }^{1,75}$ A recent metaanalysis of 9 trials, comparing prophylactic ibuprofen (oral or intravenous) with a placebo or no treatment, revealed that ibuprofen decreases the risk of PDA on day 3 to 4 of life when it is given at $<24$ hours of life (RR 0.39; 95\% CI 0.31-0.48). ${ }^{51}$ Prophylactic ibuprofen also decreased the need for rescue treatment and surgical ligation (RR 0.17 [95\% CI 0.11-0.26] and RR 0.46 [95\% CI 0.22-0.96], respectively). Despite a trend toward diminished grade 3 or 4 IVH risk and a clearer risk for increased oliguria, compared with a placebo or no treatment, no difference was noted for mortality, any IVH, or chronic lung disease (CLD) with prophylactic ibuprofen. ${ }^{51}$

As a treatment strategy for symptomatic PDA, 3 doses of intravenous ibuprofen were compared with a placebo (2 studies) in a 2018 Cochrane review, and a superior rate of closure was found with ibuprofen (RR 0.62; 95\% CI $0.44-0.86) .^{76}$ On the basis of 24 studies, ibuprofen in either an oral or intravenous route appears to be as effective as indomethacin, with an improved safety profile (reduced ventilator days and oliguria). Oral ibuprofen is preferable to indomethacin in terms of risk for NEC (RR 0.41; 95\% CI 0.23-0.73). ${ }^{76}$ 


\begin{tabular}{|c|c|c|}
\hline No & Tachycardia & Yes \\
\hline No & Tachypnea & Yes \\
\hline $\begin{array}{l}\text { No need for respiratory support or oxygen, } \\
\text { stable } \mathrm{SpO}_{2} \text { and } \mathrm{PaO}_{2}\end{array}$ & Respiratory support & $\begin{array}{l}\text { Need for invasive or noninvasive } \\
\text { respiratory support } \\
\text { Worsening respiratory situation (eg, } \\
\text { increasing flow and } \mathrm{FiO}_{2} \text { on } \mathrm{HFNC} \text {; } \\
\text { increasing PEEP, PIP, and } \mathrm{Fio}_{2} \text { on CPAP; } \\
\mathrm{NIV} ; \mathrm{MV} \text { ) and frequent desaturations }\end{array}$ \\
\hline Abdomen soft, not distended & Abdominal signs and symptoms & $\begin{array}{l}\text { Abdominal distension, residual feeding } \\
\text { volume (other pre-NEC signs) }\end{array}$ \\
\hline Not present & Signs of organ dysfunction & $\begin{array}{l}\text { Renal failure, NEC, impaired NIRS } \\
\text { variables }\end{array}$ \\
\hline $\begin{array}{l}\text { - LA only mildly dilated LAAo } \leq 1.2 \text { (PLAX) } \\
\text { - Normal LV size } \\
\text { - Dormal systolic LV function (LVEF } \geq 55 \% \text { ) } \\
\text { - PDA Vmax } \geq 3 \mathrm{~m} / \mathrm{s} \text { (CW Doppler) } \\
\text { - Ductal systolic and diastolic left-to-right } \\
\text { flow } \geq 2 \mathrm{~m} / \mathrm{s} \text { (continuous) usually indicates } \\
\text { narrowing (closing) PDA } \\
\text { - Normal mean and diastolic PA flow } \\
\text { - ACA RI } \leq 0.75 \\
\text { - No (or only early) diastolic retrograde DAO } \\
\text { flow }\end{array}$ & $\begin{array}{l}\text { Echocardiography, } \\
\text { Doppler sonography } \\
\text { (cerebral, abdominal) }\end{array}$ & $\begin{array}{l}\text { - Severe LA dilation LAVA } \geq 1.4 \text { (PLAX) } \\
\text { - Severe LV dilation ( } 4 \mathrm{C} \text { view, PSAX) } \\
\text { - Systolic LV dysfunction (LVEF }<50 \% \text { ) } \\
\text { - Ductal diameter } \geq 2 \text { to } 3 \mathrm{~mm} \text { (at narrowest } \\
\text { ID) or ductal diameter greater than or equal to } \\
\text { MPA diameter } \\
\text { - PDA Vmax } \leq 2 \mathrm{~m} / \mathrm{s} \text { (CW, unrestrictive) } \\
\text { Ductal left-to-right diastolic flow } \geq 0.5 \mathrm{~m} / \mathrm{s} \\
\text { - Highly elevated mean + diastolic PA flow } \\
\text { - Severe PA dilation (eg, LPA }>\text { AAO) } \\
\text { - ACA RI } \geq 0.9 \\
\text { - Holodiastolic retrograde DAO flow (steal) }\end{array}$ \\
\hline
\end{tabular}

\section{FIGURE 2}

Determinants of risk for preterm infants with an hsPDA. AA0, ascending aorta; ACA, anterior cerebral artery; CPAP, continuous positive airway pressure; $\mathrm{CW}$, continuous wave; DAO, descending aorta; $\mathrm{FlO}_{2}$, fraction of inspired oxygen; HFNC, high-flow nasal cannula; ID, inner diameter; LA/Ao, left atrium to aortic root diameter ratio; LPA, left pulmonary artery; LVEF, left ventricular ejection fraction; MPA, mean pulmonary artery; MV, mechanical ventilation; NIRS, near-infrared spectroscopy; NIV, noninvasive ventilation; PEEP, positive end-expiratory pressure; PIP, positive inspiratory pressure; PLAX, parasternal short axis; PSAX, parasternal short axis; RI, resistance index; $\mathrm{Sp}_{2}$, pulse oxygen saturation; Vmax, maximum velocity.

In terms of efficacy of hsPDA closure, a 2018 network meta-analysis favored high-dose oral ibuprofen over other agents. ${ }^{32}$ However, a comparative effectiveness study of indomethacin, ibuprofen, and paracetamol in infants at $<28$ weeks' gestation favored indomethacin in this regard ${ }^{73}$; rectal ibuprofen may also be effective. ${ }^{77}$ Newer strategies to disrupt prostaglandin signaling include combined COX inhibitor treatments ${ }^{78,79}$ or the potential use of compounds that could selectively inhibit PGE receptors. ${ }^{80}$ To summarize, on the basis of meta-analyses and the original TIPP trial, ${ }^{81}$ although intravenous ibuprofen is an effective agent for prophylactic use, intravenous indomethacin is favored because of reduction in IVH incidence. For treatment strategies (as opposed to prophylaxis), ibuprofen and indomethacin are likely equivalent (Table 2), although the safety profile of ibuprofen is superior.

\section{Paracetamol (Acetaminophen)}

Paracetamol is an attractive option in cases in which COX inhibitors are contraindicated or ineffective. A recent systematic review of studies comparing oral paracetamol with intravenous ibuprofen (559 infants), intravenous indomethacin (277 infants), and a placebo (80 infants) identified moderate-quality evidence suggesting that paracetamol is as effective as ibuprofen, with less gastrointestinal bleeding and lower serum creatinine levels. ${ }^{50}$ In contrast, the initial constriction rate was only $27 \%$ with paracetamol, that is, lower than with either indomethacin and ibuprofen ${ }^{73}$; of note, this trial (PDATOLERATE) was conducted in infants with an average gestation of 26 weeks, unlike more mature infants studied in recent meta-analyses. ${ }^{73}$ Moreover, a randomized trial on the efficiency of treatment of hsPDA by using either intravenous paracetamol or intravenous indomethacin in 37 very low birth weight (VLBW) infants ( $<32$ weeks' gestation, $\leq 1500$ g, first 
TABLE 2 Current Pharmacologic Treatment Strategies for PDA in the Preterm Infant

\begin{tabular}{|c|c|c|c|c|c|}
\hline & $\begin{array}{l}\text { Drug(s) of } \\
\text { Choice }\end{array}$ & Dosing & Comments & Pros & Cons \\
\hline $\begin{array}{l}\text { Targeted } \\
\text { prophylaxis in } \\
\text { at-risk infants } \\
\text { (6-24 h after } \\
\text { birth) }\end{array}$ & Indomethacin ${ }^{a}$ & $\begin{array}{l}3 \times 0.1 \mathrm{mg} / \mathrm{kg} \text { per } \\
\text { dose IV every } \\
12 \mathrm{~h}^{\mathrm{b}} \text { (single- } \\
\text { dose } \\
\text { prophylaxis may } \\
\text { be considered) }\end{array}$ & $\begin{array}{l}\text { Do not start treatment within } \\
\text { the first } 6 \mathrm{~h} \text { of life. It is } \\
\text { recommended not to use } \\
\text { ibuprofen (IV) in the first } \\
24 \mathrm{~h} \text { of life (increased risks } \\
\text { for renal failure, } \\
\text { gastrointestinal hemorrhage, } \\
\text { and possibly PPHN) }\end{array}$ & $\begin{array}{l}\text { Prevention of IVH (prophylaxis); } \\
\text { risk reduction of pulmonary } \\
\text { hemorrhage; association } \\
\text { with beneficial } \\
\text { neurodevelopmental } \\
\text { outcome in boys }\end{array}$ & $\begin{array}{l}\text { Unnecessary treatment of many } \\
\text { infants without an hsPDA }\end{array}$ \\
\hline \multirow[t]{2}{*}{$\begin{array}{l}\text { Early targeted } \\
\text { treatment of } \\
\text { infants with } \\
\text { PDA ( }<6 \mathrm{~d} \\
\text { after birth) }\end{array}$} & Indomethacin ${ }^{a}$ & $\begin{array}{l}1 \times 0.2 \mathrm{mg} / \mathrm{kg} \text { per } \\
\text { dose IV, } \\
\text { followed by } 2 \times \\
0.1 \mathrm{mg} / \mathrm{kg} \text { per } \\
\text { dose every } \\
12 \mathrm{~h}^{\mathrm{b}}\end{array}$ & $\begin{array}{l}\text { It is recommended not to use } \\
\text { ibuprofen (IV) in the first } \\
24 \mathrm{~h} \text { of life (increased risks } \\
\text { for renal failure, } \\
\text { gastrointestinal hemorrhage, } \\
\text { and possibly PPHN). }\end{array}$ & $\begin{array}{l}\text { Risk reduction of pulmonary } \\
\text { hemorrhage; possible risk } \\
\text { reduction of in-hospital } \\
\text { mortality }\end{array}$ & $\begin{array}{l}\text { Unnecessary treatment of some } \\
\text { infants who have a small PDA } \\
\text { that is hemodynamically not } \\
\text { significant; unclear effects on } \\
\text { outcome }\end{array}$ \\
\hline & Ibuprofen ${ }^{c}$ & $\begin{array}{l}10 \mathrm{mg} / \mathrm{kg} \text { per dose } \\
\mathrm{P0} \text { or IV, } \\
\text { followed by } \\
5 \mathrm{mg} / \mathrm{kg} \text { at } 24 \\
\text { and } 48 \mathrm{~h} \text { of } \\
\text { treatment start }\end{array}$ & - & - & - \\
\hline $\begin{array}{l}\text { Treatment in } \\
\text { symptomatic } \\
\text { infants with } \\
\text { hsPDA ( } \geq 6 \mathrm{~d} \\
\text { after birth) }\end{array}$ & Ibuprofen ${ }^{c}$ & $\begin{array}{l}10 \mathrm{mg} / \mathrm{kg} \text { per dose } \\
\mathrm{PO} \text { or IV, } \\
\text { followed by } \\
5 \mathrm{mg} / \mathrm{kg} \text { at } 24 \\
\text { and } 48 \mathrm{~h} \text { of } \\
\text { treatment start }\end{array}$ & $\begin{array}{l}\text { Higher doses might be } \\
\text { considered. }\end{array}$ & $\begin{array}{l}\text { Treatment only in infants with } \\
\text { hsPDA }\end{array}$ & $\begin{array}{l}\text { No evidence for beneficial long- } \\
\text { term outcome if administered } \\
\text { late }(>6-14 \mathrm{~d} \text { ); might still be } \\
\text { associated with adverse } \\
\text { outcome (eg, BPD) due to } \\
\text { a longer duration of } \\
\text { a significant shunt }\end{array}$ \\
\hline Rescue treatment & Paracetamol & $\begin{array}{c}15 \text { mg/kg per dose } \\
\text { P0 or IV every } \\
6 \mathrm{~h} \text { for } 3-7 \mathrm{~d}\end{array}$ & $\begin{array}{l}\text { Might be attempted in selected } \\
\text { infants after failed standard } \\
\text { COX inhibitor treatment; can } \\
\text { also be applied earlier if } \\
\text { contraindications for } \\
\text { standard COX inhibitor use } \\
\text { are present }\end{array}$ & $\begin{array}{l}\text { Might prevent the use of more } \\
\text { invasive measures, such as } \\
\text { ligation or catheter } \\
\text { intervention; no known renal } \\
\text { or gastrointestinal side } \\
\text { effects }\end{array}$ & $\begin{array}{l}\text { Unclear effect on } \\
\text { neurodevelopmental outcome }\end{array}$ \\
\hline
\end{tabular}

IV, intravenously; P0, per os (orally); PPHN, persistent pulmonary hypertension of the neonate; - , not applicable.

a Infuse over at least $30 \mathrm{~min}$.

b Last indomethacin dose might be omitted if echocardiography suggests pressure restrictive (closing) PDA.

c Oral ibuprofen should be followed by $2 \mathrm{~mL} / \mathrm{kg}$ water or milk (hyperosmolarity)

21 postnatal days) confirmed the aforementioned findings: the primary hsPDA closure rate with intravenous paracetamol was much lower (5.9\%; 1 of 17) than the success rate with intravenous indomethacin (55\%; 11 of 20 ), so more patients treated with paracetamol underwent transcatheter PDA closure (47\% vs $15 \%)^{82}$

\section{Timing of Pharmacologic Treatment}

The TIPP trial revealed a reduction in IVH incidence with the use of indomethacin as prophylaxis but failed to confirm a benefit on a composite outcome of survival and neurodevelopment at 18 months. ${ }^{40} \mathrm{~A}$ longer follow-up study at 3 to 8 years revealed a modest sex effect favoring prophylactic treatment in boys. ${ }^{83}$ Spontaneous closure rate varies substantially by center and is an important factor when deciding to use prophylaxis. ${ }^{47}$ Given that prophylactic ibuprofen is less efficient in preventing grades 3 and $4 \mathrm{IVH}$, indomethacin is usually considered the drug of choice for prophylaxis in selected infants. ${ }^{51}$ Additionally, longer prophylactic indomethacin courses decreased moderate-tosevere white matter injury in a prospective brain MRI study. ${ }^{84}$ However, given the high spontaneous closure rate, prophylaxis may only be justifiable for certain subgroups (see below). There are insufficient data on paracetamol use for hsPDA prophylaxis and risk of IVH (a small prospective study did not reveal a benefit on severe IVH). ${ }^{85}$ Prophylactic use of indomethacin, ibuprofen, or paracetamol has no effect on NEC, ${ }^{40,50,86}$ and studies on the according BPD risk had ambiguous results.

In the PDA-TOLERATE trial, researchers examined the effect of prolonged exposure to a moderate-tolarge PDA shunt in infants $<28$ weeks' gestational age, an important distinction to previous trials because enrollment of infants who would 
spontaneously close their PDA (41\% of those screened) was avoided. ${ }^{47}$

The PDA-TOLERATE trial suggests that early ( $<6$ days) targeted pharmacologic treatment of infants $<28$ weeks' gestational age with a significant shunt and need for respiratory support is of benefit, but in the absence of these characteristics, conservative management is acceptable.

In an Italian retrospective multicenter study, ELGANs born at 23 to 24 weeks' gestation had the highest risk of developing hsPDA refractory to pharmacologic treatment requiring surgical closure (562 of 842 $[67 \%]),{ }^{74}$ highlighting the need for individualized strategies for timely hsPDA management in this very immature population.

\section{Catheter-Based Interventional Closure of the DA in Preterm Infants}

Transcatheter device closure of the PDA has recently become more widely available. The Amplatzer Piccolo Occluder device (Amplatzer Duct Occluder II Additional Sizes, Abbott Medical Devices, Abbott Park, IL) recently received US Food and Drug Administration approval for PDA closure in premature infants weighing $\geq 700$ g. In a multicenter trial of 200 patients, the Amplatzer Duct Occluder II Additional Sizes implant success rate was 95.5\% (191 of 200) overall and 99\% in those weighing 700 to $2000 \mathrm{~g}$ (99 of 100; age $1.25 \pm 0.60$ months). ${ }^{87}$ The effective closure rate at the 6-month follow-up echocardiogram, defined as no or trivial residual PDA shunt, was $100 \%$ in patients $\leq 2000 \mathrm{~g}$ and $98.8 \%$ $>2000$ g. Four patients experienced a primary safety end point event $(2$ transfusions, 1 hemolysis, and 1 aortic obstruction). ${ }^{87}$ Additionally, 5 patients $<2000 \mathrm{~g}$ (5\%) developed new-onset moderate tricuspid regurgitation post procedure, likely related to tricuspid valve trauma during the procedure. This complication was not seen in patients
$>2000$ g. There were no instances of left PA obstruction at the 6-month follow-up. Vascular complications are rare because the procedure is performed by using venous access only. The device is delivered entirely inside the PDA to avoid obstruction of the left PA and/or the aortic arch. Although fluoroscopy is necessary, device position and effect on adjacent structures is primarily assessed by using intraprocedural

echocardiography, reducing exposure to iodinated contrast and radiation.

The procedure can be performed in the catheterization laboratory or at the bedside (by using a mobile C-arm). Although there has not been an RCT comparing device closure with surgical ligation, early experience suggests that post ligation cardiac syndrome ${ }^{88,89}$ may be less common and that improvement in respiratory status may be faster after device closure. ${ }^{90}$ Although these types of catheter devices provide the health care community with a nonsurgical alternative to achieve definitive ductal closure, important questions on the optimal use of the device, such as long-term outcome, timing, and setting of the catheter intervention, need to be answered by future studies.

\section{Surgical Ligation of the DA}

The PDA ligation rate in a US cohort of infants at 23 to 30 weeks' gestation decreased from $8.4 \%$ in 2006 to $2.9 \%$ in 2015 with an accompanying shift in the age at ligation (8 days in 2006 vs 22 days in 2015). ${ }^{91}$ This trend is consistent with those of other large cohort studies. $^{72,92-94}$ Prophylactic and early ligation approaches are no longer indicated, ${ }^{95}$ but there remains uncertainty about when and for whom ligation has clinical benefit.

In a meta-analysis of 39 cohort studies and 1 RCT, ligation compared with medical treatment was found to be associated with increased odds of neurodevelopmental impairment, CLD, and severe retinopathy of prematurity (ROP) but decreased odds of death. ${ }^{96}$ Comparing pharmacotherapy plus ligation versus conservative treatment revealed a decrease in mortality with pharmacotherapy plus surgical ligation but increased odds of CLD and severe ROP. ${ }^{96}$

As surgical ligation rates decline, clinicians must still respect the complications of this procedure, which may be present in up to $44 \%$ of infants. ${ }^{97}$ The major complications include postligation cardiac syndrome, ${ }^{98-100}$ acute kidney injury, ${ }^{101}$ vocal cord paralysis, prolonged mechanical ventilation, and BPD. ${ }^{102}$

\section{Conservative Treatment of PDA}

The specifics of conservative management are not well defined. The spectrum extends from PDA nontreatment ${ }^{2,103}$ to intentional use of fluid restriction, targeted ventilation strategies, and diuretic therapy to counteract the effects of PDA shunt while waiting for spontaneous closure. ${ }^{1,8,104}$ In 2 Cochrane reviews in which the comparisons were placebo or no treatment versus ibuprofen or paracetamol, there was no increase in death, duration of mechanical ventilation, or incidence of CLD, NEC, periventricular leukomalacia, or all grades of IVH in the placebo or no treatment group. ${ }^{50,51}$ The PDATOLERATE trial provides evidence that conservative management is no worse and may be more beneficial compared to active treatment ${ }^{47}$ in select settings.

In an observational study of the natural history of hsPDA in preterm infants at $<28$ weeks' gestation who were managed with fluid restriction, 111 of 195 infants developed hsPDA beyond the first week of life. ${ }^{2}$ No infant received pharmacotherapy or surgical ligation before discharge. There was no difference in hospital mortality or incidence of IVH, ROP, BPD, NEC, or sepsis in those with and 
without a hsPDA. The duration of PDA exposure by weekly increments did not affect outcomes. Only 2 infants required device closure after hospital discharge. ${ }^{2}$

In a recent South Korean singlecenter, double-blind, placebocontrolled, noninferiority RCT, 146 preterm infants (23-30 weeks' gestation) diagnosed with hsPDA between postnatal days 6 and 14 were studied. In contrast to the aforementioned 2018 network metaanalysis, ${ }^{32}$ in this RCT, the authors report nonintervention to be noninferior versus oral ibuprofen treatment in closing hsPDA and reducing the rate of $B P D$ or death, probably because of the low efficacy of oral ibuprofen, especially in the 41 of 83 total infants born at 23 to 26 weeks' gestation. ${ }^{105}$

The California Perinatal Quality Care Collaborative data were recently interrogated to evaluate the effect on mortality in declining COX inhibitor usage from 2008 to 2015. Mortality improvement was slowed in the 400to 749-g birth weight cohort in NICUs with reduced COX inhibitor use, ${ }^{106}$ suggesting an overlooked treatment benefit in this group. Conversely, in infants 1000 to $1499 \mathrm{~g}$, a decreasing ligation rate was associated with a reduction in BPD rates. ${ }^{106}$

In summary, as for many aspects of PDA care, conservative management is likely appropriate for subgroups of preterm infants but not all.

\section{Comprehensive Approach to Preterm} Infants With PDA

Several different strategies exist to manage infants with PDA. As discussed earlier, if PDA-targeted treatment is attempted, 4 main approaches can be differentiated: (1) early targeted prophylaxis $(<24$ hours), (2) targeted therapy of asymptomatic infants $(<6$ days after birth), (3) symptomatic treatment when the PDA becomes hemodynamically relevant ( $\geq 6$ days after birth), and (4) late symptomatic treatment after watchful waiting or rescue treatment after previously failed treatment. In Fig 3, we present a treatment algorithm that incorporates these 4 main treatment categories into a stepwise approach; the details on drug therapy are summarized in Table 2. However, it should be noted that these recommendations are based primarily on expert opinion and only provide a framework that needs to be adapted and modified to local practices:

1. Targeted early prophylaxis of PDA (indomethacin): Because of the high risk of exposing infants to adverse drug effects without clear benefit, targeted early prophylaxis should only be attempted in units with a low rate of spontaneous closure in carefully selected infants (eg, infants $<26$ weeks' gestation, $<750 \mathrm{~g}$ ). Indomethacin is usually considered the agent of choice for prophylactic treatment ${ }^{42}$ (Table 2).

Paracetamol may have fewer side effects than indomethacin or ibuprofen, but there is insufficient evidence on neurodevelopmental implications to recommend it for prophylaxis.

2. Early targeted treatment of PDA: Pharmacologic treatment is recommended at $<6$ days for infants $<28$ weeks' gestational age with a moderate-to-large hemodynamically significant shunt (Fig 2) and greater than minimal respiratory support (eg, $>2 \mathrm{~L}$ nasal cannula flow, $>0.25$ fraction of inspired oxygen). This recommendation implies echocardiographic screening of all infants $<28$ weeks' gestational age who are on any respiratory support before 6 days of postnatal life. In the absence of significant respiratory support (asymptomatic infants) or a moderate-to-large hemodynamically significant shunt (small PDA), a conservative approach may be justified.

3. Treatment of symptomatic infants with hsPDA: All VLBW infants $\geq 6$ days of age with greater than minimal respiratory support should be echocardiographically screened for PDA. In the presence of a moderate-to-large hsPDA and additional risk factors, such as failure of ventilator weaning and fraction of inspired oxygen $>0.25$ (Fig 2), treatment may be considered (Table 2, Fig 3), although positive effects on longterm outcome have not been established. Ibuprofen is usually considered as the first drug of choice (favorable safety profile versus indomethacin).

4. Late and rescue treatment of symptomatic infants with PDA: For infants with a moderate-to-large PDA shunt and more than minimal respiratory support, there are no RCTs evaluating pharmacologic closure versus catheter-based closure versus surgical ligation. Common sense would suggest a trial of pharmacologic closure first. After failed COX inhibitor treatment, rescue use of paracetamol might be attempted, although the success rate may be low. ${ }^{107,108}$ Recommendations for either catheter-based closure or surgical ligation post discharge vary among tertiary institutions and depend on the local experience (Table 2).

\section{Discharge of the Preterm Infant With} PDA

The majority of infants discharged with a PDA will still experience closure by 1 year of age; current best evidence suggests that it is safe to leave a small PDA untreated at discharge but with appropriate follow-up. ${ }^{5-7}$ There is a need for prospective research on rates of spontaneous postdischarge closure rates of infants with and without cardiorespiratory sequelae (BPD and 


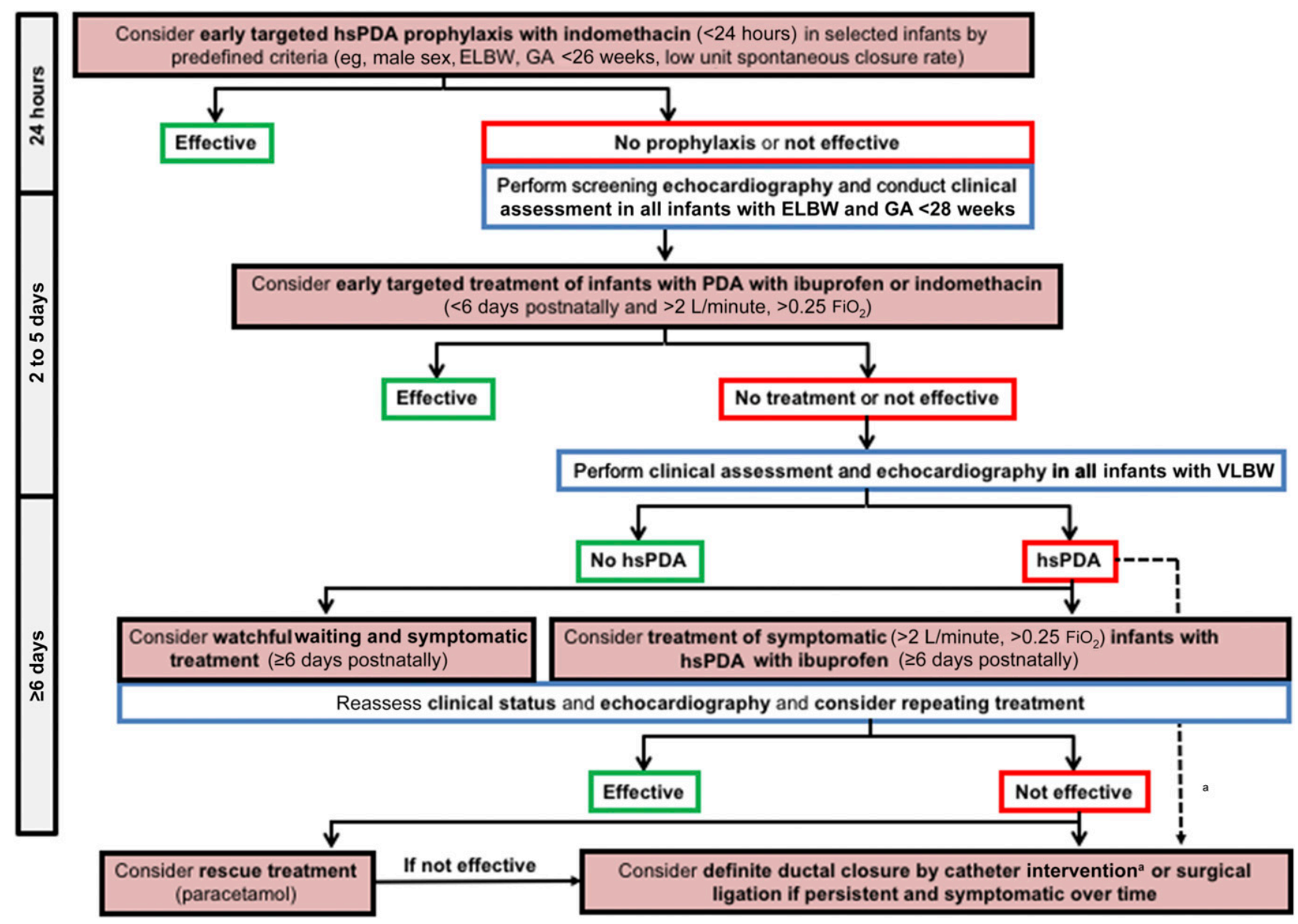

FIGURE 3

Treatment algorithm of PDA in the preterm infant. The proposed treatment algorithm incorporates the following 4 main treatment categories into a stepwise approach: (1) early targeted prophylaxis, (2) targeted therapy of asymptomatic infants ( $<6$ days after birth), (3) symptomatic treatment of hsPDA ( $\geq 6$ days after birth), and (4) late symptomatic treatment after watchful waiting or rescue treatment (for details, see main text). The details on drug therapy are summarized in Table 2. Of note, these recommendations are mostly based on expert opinion and only provide a framework that needs to be adopted and modified to local practices. For example, given the wide variance in spontaneous constriction (8\%-78\% in screened PDA-TOLERATE infants $<28$ weeks' GA in first week of life), it is first important to know your unit's spontaneous closure rate. There may be unrecognized factors (eg, genetics, altitude, echo interpretation, fluid, or respiratory management) that determine unit variability. In addition, the optimal indication and timing of catheterbased interventions (especially in comparison to surgical ligation) have not yet been clearly defined, and thus there is a large variability of its use among different neonatal units. ${ }^{a}$ Some units attempt for early catheter intervention (eg, after the first failed pharmacologic treatment cycle. ELBW, extremely low birth weight $(<1000 \mathrm{~g}) ; \mathrm{FiO}_{2}$, fraction of inspired oxygen; $\mathrm{GA}$, gestational age.

pulmonary hypertension) of prematurity (Table 3$)^{7}$

\section{CONCLUSIONS}

In the last decade, there has been a trend for less aggressive treatment of PDA in preterm infants. However, a subgroup of infants will likely benefit from intervention, be it pharmacologic, interventional, or surgical: (1) prophylactic intravenous indomethacin in highly selected ELGANs with PDA $(<26+0 / 7$ weeks' gestation, $<750 \mathrm{~g}$ birth weight; NICUs with low spontaneous closure rate); (2) early targeted therapy of PDA in selected preterm infants at particular high risk for PDA-associated complications; and (3) PDA ligation, catheter intervention, or oral paracetamol may be considered as rescue options for hsPDA closure. The impact of catheter-based interventional closure of hsPDA on clinical outcomes should be determined in prospective studies. We provide a novel treatment algorithm for PDA in preterm infants that integrates several treatment modalities in a staged approach. Our approach is somewhat limited by the lack of sufficient clinical trial data in all areas of PDA closure (expert opinion only) but is still useful for clinical guidance and for opening a debate. The recommendations of hsPDA management in the preterm infant made in this article may be adapted to local practices, and this in turn may help inform future recommendations. Comparative validation studies on the different treatment options in clearly defined at-risk populations are required. 


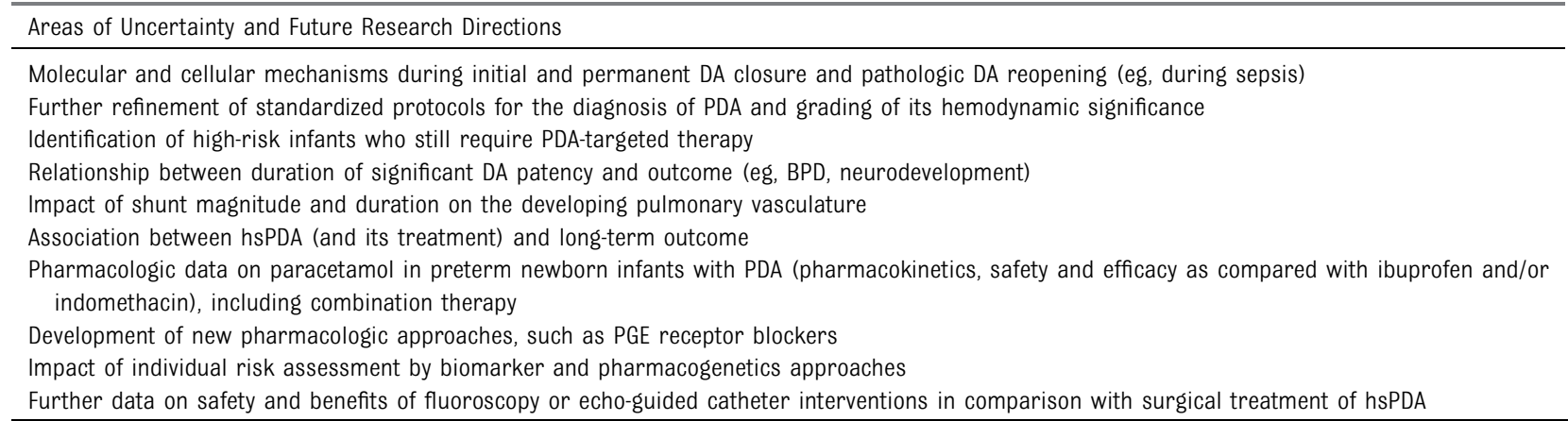

\author{
ABBREVIATIONS \\ BPD: bronchopulmonary dysplasia \\ CI: confidence interval \\ CLD: chronic lung disease \\ COX: cyclooxygenase \\ DA: ductus arteriosus \\ ELGAN: extremely low gestational \\ age newborn \\ FIP: focal intestinal perforation \\ hsPDA: hemodynamically signifi- \\ cant patent ductus \\ arteriosus \\ IVH: intraventricular hemorrhage \\ LA: left atrium \\ LV: left ventricle \\ NEC: necrotizing enterocolitis \\ PA: pulmonary artery \\ PAA: pharyngeal arch artery \\ PDA: patent ductus arteriosus \\ PDA-TOLERATE: Patent Ductus \\ Arteriosus: To \\ Leave It Alone or \\ Respond and \\ Treat Early \\ PGE: prostaglandin E \\ PVR: pulmonary vascular \\ resistance \\ RCT: randomized controlled trial \\ ROP: retinopathy of prematurity \\ RR: relative risk \\ TIPP: Trial of Indomethacin Pro- \\ phylaxis in Preterms \\ VLBW: very low birth weight
}


POTENTIAL CONFLICT OF INTEREST: The authors have indicated they have no potential conflicts of interest to disclose.

\section{REFERENCES}

1. Hamrick SE, Hansmann G. Patent ductus arteriosus of the preterm infant. Pediatrics. 2010;125(5): 1020-1030

2. Sung SI, Chang YS, Kim J, Choi JH, Ahn SY, Park WS. Natural evolution of ductus arteriosus with noninterventional conservative management in extremely preterm infants born at 23-28 weeks of gestation. PLoS One. 2019;14(2): e0212256

3. Clyman RI. Ibuprofen and patent ductus arteriosus. N Engl J Med. 2000; $343(10): 728-730$

4. Gillam-Krakauer M, Hagadorn Jl, Reese J. Pharmacological closure of the patent ductus arteriosus: when treatment still makes sense. J Perinatol. 2019;39(11):1439-1441

5. Weber SC, Weiss K, Bührer C, Hansmann G, Koehne P, Sallmon H. Natural history of patent ductus arteriosus in very low birth weight infants after discharge. J Pediatr. 2015;167(5):1149-1151

6. Herrman K, Bose C, Lewis K, Laughon M. Spontaneous closure of the patent ductus arteriosus in very low birth weight infants following discharge from the neonatal unit. Arch Dis Child Fetal Neonatal Ed. 2009;94(1):F48-F50

7. Ansems SM, Kirpalani H, Mercer-Rosa $L$, et al. Patent ductus arteriosus and the effects of its late closure in preterm infants with severe bronchopulmonary dysplasia. Neonatology. 2019;116(3):236-243

8. Vanhaesebrouck S, Zonnenberg I, Vandervoort $P$, Bruneel $E$, Van Hoestenberghe MR, Theyskens C. Conservative treatment for patent ductus arteriosus in the preterm. Arch Dis Child Fetal Neonatal Ed. 2007;92(4): F244-F247

9. Brooks JM, Travadi JN, Patole SK, Doherty DA, Simmer K. Is surgical ligation of patent ductus arteriosus necessary? The Western Australian experience of conservative management. Arch Dis Child Fetal Neonatal Ed. 2005;90(3):F235-F239

10. Noori S, McCoy M, Friedlich P, et al. Failure of ductus arteriosus closure is associated with increased mortality in preterm infants. Pediatrics. 2009; 123(1). Available at: https://pediatrics. aappublications.org/content/123/1/ e138

11. Wang X, Chen D, Chen K, Jubran A, Ramirez A, Astrof $S$. Endothelium in the pharyngeal arches 3, 4 and 6 is derived from the second heart field. Dev Biol. 2017;421(2):108-117

12. Lewis TR, Shelton EL, Van Driest SL, Kannankeril PJ, Reese J. Genetics of the patent ductus arteriosus (PDA) and pharmacogenetics of PDA treatment. Semin Fetal Neonatal Med. 2018;23(4): 232-238

13. Bökenkamp R, DeRuiter MC, van Munsteren C, Gittenberger-de Groot AC. Insights into the pathogenesis and genetic background of patency of the ductus arteriosus. Neonatology. 2010; 98(1):6-17

14. Rooney SR, Shelton EL, Aka I, et al. CYP2C9*2 is associated with indomethacin treatment failure for patent ductus arteriosus. Pharmacogenomics. 2019;20(13): 939-946

15. Smith CJ, Ryckman KK, Bahr TM, Dagle JM. Polymorphisms in CYP2C9 are associated with response to indomethacin among neonates with patent ductus arteriosus. Pediatr Res. 2017;82(5):776-780

16. Crockett SL, Berger CD, Shelton EL, Reese J. Molecular and mechanical factors contributing to ductus arteriosus patency and closure. Congenit Heart Dis. 2019;14(1):15-20

17. Stoller JZ, Demauro SB, Dagle JM, Reese J. Current perspectives on pathobiology of the ductus arteriosus. $J$ Clin Exp Cardiolog. 2012;8(1):S8-1

18. Shelton EL, Waleh N, Plosa EJ, et al. Effects of antenatal betamethasone on preterm human and mouse ductus arteriosus: comparison with baboon data. Pediatr Res. 2018;84(3):458-465

19. Hong Z, Kutty S, Toth PT, et al. Role of dynamin-related protein 1 (Drp1)mediated mitochondrial fission in oxygen sensing and constriction of the ductus arteriosus. Circ Res. 2013; 112(5):802-815

20. Yokoyama U, Minamisawa S, Shioda A, et al. Prostaglandin E2 inhibits elastogenesis in the ductus arteriosus via EP4 signaling. Circulation. 2014; 129(4):487-496

21. Echtler K, Stark K, Lorenz M, et al. Platelets contribute to postnatal occlusion of the ductus arteriosus. Nat Med. 2010;16(1):75-82

22. Semberova J, Sirc J, Miletin J, et al. Spontaneous closure of patent ductus arteriosus in infants $\leq 1500 \mathrm{~g}$. Pediatrics. 2017;140(2):e20164258

23. Jin MH, Yokoyama U, Sato Y, et al. DNA microarray profiling identified a new role of growth hormone in vascular remodeling of rat ductus arteriosus. J Physiol Sci. 2011;61(3):167-179

24. Goyal R, Goyal D, Longo LD, Clyman RI. Microarray gene expression analysis in ovine ductus arteriosus during fetal development and birth transition. Pediatr Res. 2016;80(4):610-618

25. Waleh N, Barrette AM, Dagle JM, et al. Effects of advancing gestation and nonCaucasian race on ductus arteriosus gene expression. J Pediatr. 2015;167(5): 1033-1041.e2

26. Kajino H, Goldbarg S, Roman C, et al. Vasa vasorum hypoperfusion is responsible for medial hypoxia and anatomic remodeling in the newborn lamb ductus arteriosus. Pediatr Res. 2002;51 (2):228-235

27. Olsson KW, Jonzon A, Sindelar R. A high ductal flow velocity is associated with successful pharmacological closure of patent ductus arteriosus in infants 22-27 weeks gestational age. Crit Care Res Pract. 2012;2012:715265

28. Bapat R, Aggarwal S, Natarajan G. A right-to-left or bidirectional ductal shunt in preterm neonates: grave 
implication? Am J Perinatol. 2011;28(9): 709-714

29. Simon SR, van Zogchel L, Bas-Suárez MP, Cavallaro G, Clyman RI, Villamor E. Platelet counts and patent ductus arteriosus in preterm infants: a systematic review and meta-analysis Neonatology. 2015;108(2):143-151

30. Sallmon H, Weber SC, Hüning $B$, et al. Thrombocytopenia in the first 24 hours after birth and incidence of patent ductus arteriosus. Pediatrics. 2012; 130(3). Available at: https://pediatrics. aappublications.org/content/130/3/ e623

31. Sallmon H, Weber SC, Dirks J, et al. Association between platelet counts before and during pharmacological therapy for patent ductus arteriosus and treatment failure in preterm infants. Front Pediatr. 2018;6:41

32. Mitra S, Florez ID, Tamayo ME, et al. Association of placebo, indomethacin, ibuprofen, and acetaminophen with closure of hemodynamically significant patent ductus arteriosus in preterm infants: a systematic review and metaanalysis. JAMA. 2018;319(12):1221-1238

33. Kumar J, Dutta S, Sundaram V, Saini SS, Sharma RR, Varma N. Platelet transfusion for PDA closure in preterm infants: a randomized controlled trial. Pediatrics. 2019;143(5):e20182565

34. Sallmon H, Weber SC, von Gise A, Koehne P, Hansmann G. Ductal closure in neonates: a developmental perspective on platelet-endothelial interactions. Blood Coagul Fibrinolysis. 2011;22(3):242-244

35. Kahvecioglu D, Erdeve 0, Akduman H, et al. Influence of platelet count, platelet mass index, and platelet function on the spontaneous closure of ductus arteriosus in the prematurity. Pediatr Neonatol. 2018;59(1):53-57

36. Benitz WE. Treatment of persistent patent ductus arteriosus in preterm infants: time to accept the null hypothesis? J Perinatol. 2010;30(4): 241-252

37. Clyman RI. Patent ductus arteriosus, its treatments, and the risks of pulmonary morbidity. Semin Perinatol. 2018;42(4): 235-242

38. Hansmann G. Pulmonary hypertension in infants, children, and young adults.
J Am Coll Cardiol. 2017;69(20): 2551-2569

39. Hansmann G, Sallmon H, Roehr CC, Kourembanas S, Austin ED, Koestenberger M; European Pediatric Pulmonary Vascular Disease Network (EPPVDN). Pulmonary hypertension in bronchopulmonary dysplasia [published online ahead of print Jun 10, 2020]. Pediatr Res. doi:10.1038/s41390020-0993-4

40. Schmidt B, Davis P, Moddemann D, et al.; Trial of Indomethacin Prophylaxis in Preterms Investigators. Long-term effects of indomethacin prophylaxis in extremely-low-birth-weight infants. N Engl J Med. 2001;344(26):1966-1972

41. Alfaleh KM, Al Luwaimi E, Alkharfi TM, AlAlaiyan SA. A decision aid for considering indomethacin prophylaxis vs. symptomatic treatment of PDA for extreme low birth weight infants. $B M C$ Pediatr. 2011;11:78

42. Kluckow M, Jeffery M, Gill A, Evans N. A randomised placebo-controlled trial of early treatment of the patent ductus arteriosus. Arch Dis Child Fetal Neonatal Ed. 2014;99(2):F99-F104

43. Saldeño YP, Favareto V, Mirpuri J. Prolonged persistent patent ductus arteriosus: potential perdurable anomalies in premature infants. J Perinatol. 2012;32(12):953-958

44. Schena F, Francescato G, Cappelleri A, et al. Association between hemodynamically significant patent ductus arteriosus and bronchopulmonary dysplasia. J Pediatr. 2015;166(6):1488-1492

45. Mirza H, Garcia J, McKinley G, et al. Duration of significant patent ductus arteriosus and bronchopulmonary dysplasia in extremely preterm infants. J Perinatol. 2019;39(12):1648-1655

46. Gudmundsdottir A, Johansson $S$, Håkansson S, Norman M, Källen K, Bonamy AK. Timing of pharmacological treatment for patent ductus arteriosus and risk of secondary surgery, death or bronchopulmonary dysplasia: a population-based cohort study of extremely preterm infants. Neonatology. 2015;107(2):87-92

47. Clyman RI, Liebowitz M, Kaempf J, et al.; PDA-TOLERATE (PDA: TO LEave it alone or Respond And Treat Early) Trial
Investigators. PDA-TOLERATE trial: an exploratory randomized controlled trial of treatment of moderate-to-large patent ductus arteriosus at 1 week of age. J Pediatr. 2019;205:41-48.e6

48. Liebowitz M, Katheria A, Sauberan J, et al.; PDA-TOLERATE (PDA: TOLEave it alone or Respond And Treat Early) Trial Investigators. Lack of equipoise in the PDA-TOLERATE trial: a comparison of eligible infants enrolled in the trial and those treated outside the trial. J Pediatr. 2019;213:222-226.e2

49. Clyman RI, Hills NK, Liebowitz M, Johng S. Relationship between duration of infant exposure to a moderate-to-large patent ductus arteriosus shunt and the risk of developing bronchopulmonary dysplasia or death before 36 Weeks. Am J Perinatol. 2020;37(2):216-223

50. Ohlsson A, Shah PS. Paracetamol (acetaminophen) for patent ductus arteriosus in preterm or low birth weight infants. Cochrane Database Syst Rev. 2020;(1):CD010061

51. Ohlsson A, Shah SS. Ibuprofen for the prevention of patent ductus arteriosus in preterm and/or low birth weight infants. Cochrane Database Syst Rev. 2020;(1):CD004213

52. Cassady G, Crouse DT, Kirklin JW, et al. A randomized, controlled trial of very early prophylactic ligation of the ductus arteriosus in babies who weighed $1000 \mathrm{~g}$ or less at birth. $N$ Engl J Med. 1989;320(23):1511-1516

53. Jhaveri N, Moon-Grady A, Clyman RI. Early surgical ligation versus a conservative approach for management of patent ductus arteriosus that fails to close after indomethacin treatment. J Pediatr. 2010;157(3):381-387, 387.e1

54. Wickremasinghe AC, Rogers EE, Piecuch $\mathrm{RE}$, et al. Neurodevelopmental outcomes following two different treatment approaches (early ligation and selective ligation) for patent ductus arteriosus. J Pediatr. 2012;161(6): 1065-1072

55. Lemmers PM, Toet MC, van Bel F. Impact of patent ductus arteriosus and subsequent therapy with indomethacin on cerebral oxygenation in preterm infants. Pediatrics. 2008;121(1):142-147 
56. Lemmers PM, Benders MJNL, D’Ascenzo $\mathrm{R}$, et al. Patent ductus arteriosus and brain volume. Pediatrics. 2016;137(4): e20153090

57. Janz-Robinson EM, Badawi N, Walker K, Bajuk B, Abdel-Latif ME; Neonatal Intensive Care Units Network. Neurodevelopmental outcomes of premature infants treated for patent ductus arteriosus: a population-based cohort study. J Pediatr. 2015;167(5): 1025-1032.e3

58. Collins RT II, Lyle RE, Rettiganti M, Gossett JM, Robbins JM, Casey PH. Long-term neurodevelopment of lowbirthweight, preterm infants with patent ductus arteriosus. J Pediatr. 2018;203:170-176.e1

59. Wadhawan R, Oh W, Vohr BR, et al. Spontaneous intestinal perforation in extremely low birth weight infants: association with indometacin therapy and effects on neurodevelopmental outcomes at 18-22 months corrected age. Arch Dis Child Fetal Neonatal Ed. 2013;98 (2):F127-F132

60. Clyman R, Wickremasinghe A, Jhaveri N, et al.; Ductus Arteriosus Feed or Fast with Indomethacin or Ibuprofen (DAFFII) Investigators. Enteral feeding during indomethacin and ibuprofen treatment of a patent ductus arteriosus. J Pediatr. 2013;163(2):406-411

61. Yanowitz TD, Reese J, Gillam-Krakauer $M$, et al. Superior mesenteric artery blood flow velocities following medical treatment of a patent ductus arteriosus. J Pediatr. 2014;164(3): 661-663

62. Kelleher J, Salas AA, Bhat R, et al.; GDB Subcommittee, Eunice Kennedy Shriver National Institute of Child Health and Human Development Neonatal Research Network. Prophylactic indomethacin and intestinal perforation in extremely low birth weight infants. Pediatrics. 2014;134(5). Available at: https:// pediatrics.aappublications.org/content/ 134/5/e1369

63. Jain A, Shah PS. Diagnosis, evaluation, and management of patent ductus arteriosus in preterm neonates. JAMA Pediatr. 2015;169(9):863-872

64. Sallmon H, Koehne P, Hansmann G. Recent advances in the treatment of preterm newborn infants with patent ductus arteriosus. Clin Perinatol. 2016; 43(1):113-129

65. Heuchan AM, Young D. Early colour Doppler duct diameter and symptomatic patent ductus arteriosus in a cyclo-oxygenase inhibitor naïve population. Acta Paediatr. 2013;102(3): 254-257

66. Pees C, Walch E, Obladen M, Koehne P. Echocardiography predicts closure of patent ductus arteriosus in response to ibuprofen in infants less than 28 week gestational age. Early Hum Dev. 2010; 86(8):503-508

67. Rozé JC, Cambonie G, Marchand-Martin L, et al.; Hemodynamic EPIPAGE 2 Study Group. Association between early screening for patent ductus arteriosus and in-hospital mortality among extremely preterm infants. JAMA. 2015; 313(24):2441-2448

68. Shepherd JL, Noori S. What is a hemodynamically significant PDA in preterm infants? Congenit Heart Dis. 2019;14(1):21-26

69. Chock VY, Rose LA, Mante JV, Punn R. Near-infrared spectroscopy for detection of a significant patent ductus arteriosus. Pediatr Res. 2016;80(5): 675-680

70. Ledo A, Aguar M, Núñez-Ramiro A, Saénz $P$, Vento M. Abdominal near-infrared spectroscopy detects low mesenteric perfusion early in preterm infants with hemodynamic significant ductus arteriosus. Neonatology. 2017;112(3): 238-245

71. EL-Khuffash A, James AT, Cleary A, Semberova J, Franklin 0, Miletin J. Late medical therapy of patent ductus arteriosus using intravenous paracetamol. Arch Dis Child Fetal Neonatal Ed. 2015;100(3):F253-F256

72. Ngo S, Profit J, Gould JB, Lee HC. Trends in patent ductus arteriosus diagnosis and management for very low birth weight infants. Pediatrics. 2017;139(4): e20162390

73. Liebowitz M, Kaempf J, Erdeve 0, et al. Comparative effectiveness of drugs used to constrict the patent ductus arteriosus: a secondary analysis of the PDA-TOLERATE trial (NCT01958320). J Perinatol. 2019;39(5):599-607

74. Dani C, Mosca F, Cresi F, et al. Patent ductus arteriosus in preterm infants born at 23-24 weeks' gestation: should we pay more attention? Early Hum Dev. 2019;135:16-22

75. Van Overmeire B, Smets K, Lecoutere D, et al. A comparison of ibuprofen and indomethacin for closure of patent ductus arteriosus. N Engl J Med. 2000; 343(10):674-681

76. Ohlsson A, Walia R, Shah SS. Ibuprofen for the treatment of patent ductus arteriosus in preterm or low birth weight (or both) infants. Cochrane Database Syst Rev. 2018;(9):CD003481

77. Demir N, Peker E, Ece I, Balahoroğlu R, Tuncer 0 . Efficacy and safety of rectal ibuprofen for patent ductus arteriosus closure in very low birth weight preterm infants. J Matern Fetal Neonatal Med. 2017;30(17):2119-2125

78. Hochwald 0, Mainzer G, BorensteinLevin L, et al. Adding paracetamol to ibuprofen for the treatment of patent ductus arteriosus in preterm infants: a double-blind, randomized, placebocontrolled pilot study. Am J Perinatol. 2018;35(13):1319-1325

79. Yurttutan S, Bozkaya A, Hüdayioglu F, Oncel MY. The effect of combined therapy for treatment of monotherapyresistant PDA in preterm infants. $\checkmark$ Matern Fetal Neonatal Med. 2019; 32(21):3662-3665

80. Sakuma T, Akaike T, Minamisawa S. Prostaglandin $\mathrm{E}_{2}$ receptor EP4 inhibition contracts rat ductus arteriosus. Circ J. 2018;83(1):209-216

81. Schmidt B, Roberts RS, Fanaroff A, et al.; TIPP Investigators. Indomethacin prophylaxis, patent ductus arteriosus, and the risk of bronchopulmonary dysplasia: further analyses from the Trial of Indomethacin Prophylaxis in Preterms (TIPP). J Pediatr. 2006;148(6): 730-734

82. Davidson JM, Ferguson J, Ivey E, Philip $\mathrm{R}$, Weems MF, Talati AJ. A randomized trial of intravenous acetaminophen versus indomethacin for treatment of hemodynamically significant PDAs in VLBW infants [published online ahead of print May 21, 2020]. J Perinatol. doi: 10.1038/s41372-020-0694-1

83. Ment LR, Vohr BR, Makuch RW, et al. Prevention of intraventricular hemorrhage by indomethacin in male 
preterm infants. J Pediatr. 2004;145(6): 832-834

84. Miller SP, Mayer EE, Clyman RI, Glidden DV, Hamrick SEG, Barkovich AJ. Prolonged indomethacin exposure is associated with decreased white matter injury detected with magnetic resonance imaging in premature newborns at 24 to 28 weeks' gestation at birth. Pediatrics. 2006;117(5): 1626-1631

85. Härkin P, Härma A, Aikio 0, et al. Paracetamol accelerates closure of the ductus arteriosus after premature birth: a randomized trial. J Pediatr. 2016;177:72-77.e2

86. Ohlsson A, Walia R, Shah SS. Ibuprofen for the treatment of patent ductus arteriosus in preterm or low birth weight (or both) infants. Cochrane Database Syst Rev. 2020;(2):CD003481

87. Sathanandam SK, Gutfinger D, O'Brien L, et al. Amplatzer Piccolo Occluder clinical trial for percutaneous closure of the patent ductus arteriosus in patients $\geq 700$ grams [published online ahead of print May 20, 2020]. Catheter Cardiovasc Interv. doi:10.1002/ ccd. 28973

88. Zahn EM, Peck D, Phillips A, et al. Transcatheter closure of patent ductus arteriosus in extremely premature newborns: early results and midterm follow-up. JACC Cardiovasc Interv. 2016; $9(23): 2429-2437$

89. Sathanandam S, Justino H, Waller BR III, Radtke W, Qureshi AM. Initial clinical experience with the Medtronic Micro Vascular Plug ${ }^{\mathrm{TM}}$ in transcatheter occlusion of PDAs in extremely premature infants. Catheter Cardiovasc Interv. 2017;89(6):1051-1058

90. Sathanandam S, Balduf K, Chilakala S, et al. Role of transcatheter patent ductus arteriosus closure in extremely low birth weight infants. Catheter Cardiovasc Interv. 2019;93(1):89-96

91. Bixler GM, Powers GC, Clark RH, Walker MW, Tolia VN. Changes in the diagnosis and management of patent ductus arteriosus from 2006 to 2015 in United States neonatal intensive care units. J Pediatr. 2017;189:105-112
92. Lokku A, Mirea L, Lee SK, Shah PS; Canadian Neonatal Network. Trends and outcomes of patent ductus arteriosus treatment in very preterm infants in Canada. Am J Perinatol. 2017;34(5): 441-450

93. Hagadorn Jl, Brownell EA, Trzaski JM, et al. Trends and variation in management and outcomes of very lowbirth-weight infants with patent ductus arteriosus. Pediatr Res. 2016;80(6): 785-792

94. Reese J, Scott TA, Patrick SW. Changing patterns of patent ductus arteriosus surgical ligation in the United States. Semin Perinatol. 2018;42(4):253-261

95. Mosalli R, Alfaleh K. Prophylactic surgical ligation of patent ductus arteriosus for prevention of mortality and morbidity in extremely low birth weight infants. Cochrane Database Syst Rev. 2008;(1):CD006181

96. Weisz DE, More K, McNamara PJ, Shah PS. PDA ligation and health outcomes: a meta-analysis. Pediatrics. 2014;133(4). Available at: https://pediatrics. aappublications.org/content/133/4/ e1024

97. Foster M, Mallett LH, Govande V, et al. Short-term complications associated with surgical ligation of patent ductus arteriosus in ELBW infants: a 25-year cohort study [published online ahead of print November 4, 2019]. Am J Perinatol. doi:10.1055/s-0039-1698459

98. El-Khuffash AF, Jain A, Dragulescu A, McNamara PJ, Mertens L. Acute changes in myocardial systolic function in preterm infants undergoing patent ductus arteriosus ligation: a tissue Doppler and myocardial deformation study. J Am Soc Echocardiogr. 2012; 25(10):1058-1067

99. Teixeira LS, Shivananda SP, Stephens D, Van Arsdell G, McNamara PJ. Postoperative cardiorespiratory instability following ligation of the preterm ductus arteriosus is related to early need for intervention. J Perinatol. 2008;28(12):803-810

100. Ulrich TJB, Hansen TP, Reid KJ, Bingler MA, Olsen SL. Post-ligation cardiac syndrome is associated with increased morbidity in preterm infants.

J Perinatol. 2018;38(5):537-542

101. Aygün A, Poryo M, Wagenpfeil G, et al. Birth weight, Apgar scores and gentamicin were associated with acute kidney injuries in VLBW neonates requiring treatment for patent ductus arteriosus. Acta Paediatr. 2019;108(4): 645-653

102. Henry BM, Hsieh WC, Sanna B, Vikse J, Taterra D, Tomaszewski KA. Incidence, risk factors, and comorbidities of vocal cord paralysis after surgical closure of a patent ductus arteriosus: a metaanalysis. Pediatr Cardiol. 2019;40(1): 116-125

103. Mohamed MA, El-Dib M, Alqahtani S, Alyami K, Ibrahim AN, Aly H. Patent ductus arteriosus in premature infants: to treat or not to treat? $J$ Perinatol. 2017;37(6):652-657

104. Borràs-Novell C, Riverola A, AldecoaBilbao V, Izquierdo $\mathrm{M}$, Domingo $\mathrm{M}$. Clinical outcomes after more conservative management of patent ductus arteriosus in preterm infants. J Pediatr (Rio J). 2020;96(2):177-183

105. Sung SI, Lee MH, Ahn SY, Chang YS, Park WS. Effect of nonintervention vs oral ibuprofen in patent ductus arteriosus in preterm infants: a randomized clinical trial. JAMA Pediatr. 2020;174(8): 755-763

106. Hagadorn Jl, Bennett MV, Brownell EA, Payton KSE, Benitz WE, Lee HC. Covariation of neonatal intensive care unit-level patent ductus arteriosus management and in-neonatal intensive care unit outcomes following preterm birth. J Pediatr. 2018;203:225-233.e1

107. Mashally S, Nield LE, McNamara PJ, et al. Late oral acetaminophen versus immediate surgical ligation in preterm infants with persistent large patent ductus arteriosus. J Thorac Cardiovasc Surg. 2018;156(5):1937-1944

108. Sallmon H, Koehne P. Further experience with oral paracetamol as a rescue therapy for patent ductus arteriosus in preterm infants. Pediatr Cardiol. 2018;39(2):411-412 